Mens

Revue d'histoire intellectuelle et culturelle

mens

\title{
La Grande Noirceur vue par elle-même
}

\section{Jacques Beauchemin}

Volume 18, numéro 2, printemps 2018

La Grande Noirceur

URI : https://id.erudit.org/iderudit/1066259ar

DOI : https://doi.org/10.7202/1066259ar

Aller au sommaire du numéro

Éditeur(s)

Centre de recherche en civilisation canadienne-française

ISSN

1492-8647 (imprimé)

1927-9299 (numérique)

Découvrir la revue

\section{Citer cet article}

Beauchemin, J. (2018). La Grande Noirceur vue par elle-même. Mens, 18(2), 13-38. https://doi.org/10.7202/1066259ar

\section{Résumé de l'article}

Nous avons l'habitude de rapporter la notion de Grande Noirceur et surtout sa critique à l'ébullition des années 1960 . On assiste alors au procès d'une époque apparemment honteuse dont la Révolution tranquille n’aura cessé de dénoncer les attardements traditionalistes et conservateurs. Entre les ténèbres duplessistes et les lumières de la soi-disant « modernité " qu'aurait engendrée la Révolution tranquille, ce sont deux époques fortement contrastées que nous propose habituellement l'historiographie. Il n'en demeure pas moins que le procès en question s'était institué de l'intérieur même de la dite Grande Noirceur et que les manquements que lui imputeront les années 1960 étaient déjà largement connus au cours de la décennie précédente. Nous voudrons montrer que la critique de la Grande Noirceur s'est déployée en trois temps, chacun sous une thématique dominante. C'est dans Cité libre notamment, mais en d'autres lieux également, que se dessine la première critique. Elle préfigure celle de la Révolution tranquille elle-même, tout en étant plus sévère à certains égards. Le moment fort de cette critique se situe toutefois à la charnière de ces deux mondes au moment où le conservatisme canadien-français n'a pas encore rendu les armes et que pointent les premières clartés de la Révolution tranquille.
Ce document est protégé par la loi sur le droit d'auteur. L'utilisation des services d’Érudit (y compris la reproduction) est assujettie à sa politique d'utilisation que vous pouvez consulter en ligne.

https://apropos.erudit.org/fr/usagers/politique-dutilisation/ 


\title{
La Grande Noirceur vue par elle-même
}

\author{
Jacques Beauchemin \\ Département de sociologie \\ Université du Québec à Montréal
}

\section{Résumé}

Nous avons l'habitude de rapporter la notion de Grande Noirceur et surtout sa critique à l'ébullition des années 1960. On assiste alors au procès d'une époque apparemment honteuse dont la Révolution tranquille n'aura cessé de dénoncer les attardements traditionalistes et conservateurs. Entre les ténèbres duplessistes et les lumières de la soi-disant " modernité » qu'aurait engendrée la Révolution tranquille, ce sont deux époques fortement contrastées que nous propose habituellement l'historiographie. Il n'en demeure pas moins que le procès en question s'était institué de l'intérieur même de la dite Grande Noirceur et que les manquements que lui imputeront les années 1960 étaient déjà largement connus au cours de la décennie précédente. Nous voudrons montrer que la critique de la Grande Noirceur s'est déployée en trois temps, chacun sous une thématique dominante. C'est dans Cité libre notamment, mais en d'autres lieux également, que se dessine la première critique. Elle préfigure celle de la Révolution tranquille elle-même, tout en étant plus sévère à certains égards. Le moment fort de cette critique se situe toutefois à la charnière de ces deux mondes au moment où le conservatisme canadien-français n'a pas encore rendu les armes et que pointent les premières clartés de la Révolution tranquille. 
La Grande Noirceur fait partie intégrante de l'imaginaire québécois. Elle désigne un genre de préhistoire dans laquelle le Québec n’aurait été qu'attardement et piétinement. D'une certaine façon, le vocable englobe rétrospectivement toutes les impuissances canadiennesfrançaises : un sens des affaires apparemment déficient, un interventionnisme de l'État nécessaire auquel se serait obstinément refusé un duplessisme retardataire, un antidémocratisme endémique, la soumission à une Église catholique rétrograde, etc ${ }^{1}$. Mais, en réalité, ce qui se trouve incriminé dans le constat d'un Québec captif de la tradition et du conservatisme, c'est la culture canadienne-française dans son ensemble. C'est en elle que la critique des années 1950 et 1960 trouve la source profonde de ce retard, sans doute coupable et honteux, de la société canadienne-française sur la modernité nordaméricaine. C'est en elle que se serait développé un traditionalisme responsable de l'enlisement du monde canadien-français mais aussi, comme en contrepartie, la représentation tout aussi prégnante de cette " race qui ne sait pas mourir ». Se conjuguent dans une même représentation la célébration de la résilience de la collectivité et la dénonciation d'un attachement anachronique à la tradition.

Cette attitude n'est peut-être pas étrangère à la condition des peuples dont la pérennité dans l'histoire n’est pas assurée. Parce qu'elles sont privées des moyens d'émancipation qui sont à la portée des autres, le capital, le pouvoir ou la reconnaissance, les petites sociétés ont tendance à se définir à travers le rapport subjectif qu'elles

1 Parmi les nombreux ouvrages abordant d'une manière ou d'une autre la question du retard du Québec, du poids du traditionalisme et du conservatisme, voir notamment Gilles Paquet, Oublier la Révolution tranquille : pour une nouvelle socialité, Éditions Liber, 1999; Pierre Elliott Trudeau, Le fédéralisme et la société canadienne-française, Montréal, Hurtubise HMH, 1967; René Durocher et PaulAndré Linteau, Le retard du Québec et l'infériorité économique des Canadiens français, Trois-Rivières, Éditions du Boréal Express, 1971; Nicole Laurin-Frenette, Production de l'État et formes de la nation, Montréal, Nouvelle Optique, 1978; ou encore Fernand Ouellet, "La Révolution tranquille, tournant révolutionnaire? ", dans Thomas Axworthy et Pierre Elliott Trudeau (dir.), Les années Trudeau : la recherche d'une société juste, Montréal, Éditions du Jour, 1990. 
entretiennent à elles-mêmes et qui les conduit à se représenter comme "culture ». Fernand Dumont, par exemple, écrit au sujet de la Révolution tranquille qu'elle aura été une "révolution culturelle ", dont l'essentiel aura consisté à libérer la " parole " à l'occasion d'une "levée de la censure ${ }^{2}$ ». Des discours nouveaux s'élevaient contre l'exaspération trop longtemps contenue à l'égard de la religion et de l'Église, contre la soumission et les empêchements de jadis. Dumont déplore les limites de cette « révolution de collège » et avance l'hypothèse vraisemblable selon laquelle l'histoire aurait laissé vacant l'espace de la parole que les Canadiens français, dominés sur les autres plans de leur existence collective, pouvaient investir. La Révolution tranquille n'aurait été que le prolongement libératoire et nécessaire de cette vieille propension à débattre du destin de la collectivité dans l'ordre du discours. De ce point de vue, la critique de la domination tout comme les appels à l'émancipation au cours des années 1950 et 1960 passaient par l'introspection collective, par un détour par les "idéologies », par l'analyse cent fois remise sur le métier d'une culture problématique.

Cette représentation de la culture en tant que facteur de l'aliénation collective est très ancienne dans l'histoire du Québec. Depuis la Conquête, le regard négatif que jette l'" autre " sur cette culture a engendré complexes et refus de soi. Le passage le mieux connu du rapport Durham est celui qui fait des Canadiens français de jadis " un peuple sans histoire et sans littérature ». Cet extrait, inlassablement rappelé, continue d'être l'injure suprême adressée à notre être collectif ${ }^{3}$. Pour quelles raisons cette insulte, que les réalisations culturelles du Québec ont réfutée depuis, est-elle demeurée imprimée dans les esprits au point d'avoir longtemps constitué le motif d'une revanche et d'un redressement de l'histoire? Car, en effet, le rapport

2 Fernand Dumont, La vigile du Québec, Montréal, Hurtubise HMH, 1971, p. 95-96.

3 Voir, à ce sujet, Guy Laforest, avec la collaboration de Jean-Olivier Roy, Un Québec exilé dans la fédération : essai d'histoire intellectuelle et de pensée politique, Montréal, Québec Amérique, 2014, p. 106. 
Durham évoque bien d'autres choses autrement plus déterminantes quant à l'avenir de la nation au lendemain de 1840. Une chambre d'assemblée dans laquelle les Canadiens français allaient être en minorité en vertu d'une stratégie qui ne se donnait même pas la peine de dissimuler son caractère antidémocratique allait déterminer pour longtemps le parcours de la société québécoise. Ce sont pourtant les échos lointains de ces propos attentatoires à la valeur de notre culture qui écorchent l'âme encore aujourd'hui.

Quelle est la signification de ce ressassement, sinon que cette inculture que Durham nous a jetée à la figure avive la blessure jamais cicatrisée d'un rapport défavorable à nous-mêmes? Quelle est la raison de cette autoflagellation que constitue l'incessant et douloureux rappel de ce passage du rapport, sinon que la conscience collective y trouve une part de coupable vérité? Peuple sans culture ni littérature? Pour l'essentiel, cela était vrai. À partir du moment où Durham dépose son rapport, nous attendrons six ans encore avant la publication du premier tome de L'Histoire du Canada de François-Xavier Garneau. Nous n'allions lire que 20 ans plus tard les premiers poèmes d'Octave Crémazie. Presque 25 ans s'écouleront avant que nous lisions Les anciens Canadiens d'Aubert de Gaspé. Les Canadiens français de 1840 n'avaient pas grand-chose à opposer à l'évaluation que Durham avait faite de la piètre valeur de leur culture. C'est sans doute la raison pour laquelle ils se dépêcheront d'élever Crémazie au rang de poète national, eux qui souffraient de n'en posséder aucun jusqu'à lui et, avec la même ferveur, de sacrer Garneau historien national au cours des années 1850 et $1860^{4}$.

Le rapport Durham avait soulevé la colère en même temps qu’il insinuait un doute dans la conscience collective. Peut-être n'avionsnous rien "ajouté à l'esprit humain », comme les Canadiens français

${ }^{4}$ Manon Brunet, "La constitution d'une tradition littéraire québécoise par l'institution littéraire en formation au XIX ${ }^{\mathrm{e}}$ siècle ", dans Pierre Lanthier et Guildo Rousseau (dir.), La culture inventée : les stratégies culturelles aux $19^{\circ}$ et $20^{e}$ siècles, Québec, Institut québécois de recherche sur la culture, 1992, p. 27. 
du XIX ${ }^{e}$ siècle pouvaient le lire dans le Quebec Mercury, journal voué à la défense des intérêts des marchands anglais ${ }^{5}$ ? Notre représentation de nous-mêmes fut sans doute ébranlée bien au-delà de la conjoncture des années 1840. Nous avions été dominés économiquement et politiquement et nous n'y pouvions pas grand-chose. Du haut de la Révolution tranquille, nous nous demandions pour quelles raisons nous n'avions pas trouvé dans notre culture et nos idéologies les ressorts de notre émancipation au lieu de nous enfermer dans cet attachement atavique à nos traditions, de plus en plus rétrogrades au fur et à mesure que les promesses de progrès $\mathrm{du} \mathrm{xx}^{e}$ siècle se concrétisaient ailleurs. Peut-être y a-t-il dans les tréfonds de la conscience collective un sentiment diffus de culpabilité à l'égard d'une culture qui nous tenait prisonniers d'une certaine médiocrité dont nous ne nous serions dépris que tardivement? L'idée de Grande Noirceur trouve dans cette suspicion sa signification la plus lointaine.

Cette Grande Noirceur et la pauvreté culturelle du Canada français qu'elle incarnerait, nous les avons intériorisées dans le sentiment vague d'une tare collective. L'enthousiasme avec lequel nous nous réjouissons parfois devant les brillantes réalisations de nos artistes à l'étranger est peut-être à la mesure de l'insulte que nous a lancée Durham et du rattrapage auquel nous nous sommes astreints depuis. La question la plus importante ne consiste pas tant à interroger la Grande Noirceur en tant que "mythistoire ", non plus qu’à se pencher sur un ensemble de manifestations qui accréditeraient l'idée de ce Moyen Âge québécois, mais plutôt à l'analyser du point de vue de sa signification culturelle. En d'autres termes, il nous faut peut-être appréhender la Grande Noirceur dans ce qu'elle cristallise du sentiment enfoui dans l'expérience historique québécoise d'un " problème "

5 Fernand Dumont, Genèse de la société québécoise, Montréal, Éditions du Boréal, 1993, p. 125.

${ }^{6}$ Au sujet du concept de mythistoire, voir, en particulier, Jocelyn Létourneau, "Mythistoires de Losers : introduction au roman historial des Québécois d'héritage canadien-français ", Histoire sociale = Social History, vol. 39, n 77 (mai 2006), p. $157-180$. 
culturel et de son nécessaire dépassement, ce qui sera, pour l'essentiel, le projet de la Révolution tranquille.

\section{La culture comme problème}

Alors qu'Henri Bourassa lui demande s'il a tenu compte de l'opinion du Québec quant à la participation du Canada à la guerre des Boers, Wilfrid Laurier déclare en 1899 que « [1] es Canadiens français n'ont pas d'opinions, ils n'ont que des sentiments ${ }^{7}$ ». Cette déclaration appartient elle aussi au palmarès des citations les plus connues servant à définir la culture canadienne-française. Elle la cantonne à l'univers clos de l'émotion et à un genre d'immaturité intellectuelle. C'est encore un vice logé dans la culture elle-même qui entraverait la faculté à réfléchir de façon réaliste aux enjeux auxquels est confrontée la collectivité.

D'une manière ou d'une autre, c'est le décalage par rapport à une modernité advenue ailleurs, une déficience à l'égard de la faculté de juger ou encore une culture qui n'a rien à dire au monde qui constitueraient le cœur du problème. Nulle surprise alors dans le fait que la Révolution tranquille surgira sous l'image de la renaissance miraculeuse de la collectivité au terme de l'« hiver de la survivance " dont parle Dumont. Nul étonnement non plus dans le fait que, de ce point de vue, la Grande Noirceur se posera, d'abord et avant tout, comme un problème affectant la culture ${ }^{8}$. C'est en elle que se seraient nouées nos impuissances et que reposerait de même notre nécessaire émancipation. La Révolution tranquille sera alors celle de la " parole " surgissant de ce peuple «sans culture ni littérature ».

7 Robert Rumilly, Histoire de la province de Québec, t. IX : Marchand, Montréal, Éditions Fides, 1930, p. 121, cité dans James I. W. Corcoran, "Henri Bourassa et la guerre sud-africaine (suite) ", Revue d'histoire de l'Amérique française, vol. 19, $\mathrm{n}^{\circ} 1$ (juin 1965), p. 90.

8 On trouvera un condensé particulièrement significatif de cette analyse tout entière centrée sur les effets aliénants d'une culture canadienne-française prisonnière du conservatisme, dans Marcel Rioux et Yves Martin, La société canadienne-française, Montréal, Hurtubise HMH, 1971. 
L'optimisme qui dominera sans partage les années 1960 rompt avec le sentiment d'impuissance de jadis. Il libérera les forces du changement que l'hiver de la survivance avait endiguées, mais il prolongera en termes nouveaux cette impression très ancienne dans notre histoire que nous avons un problème à régler avec notre culture. Nous savons confusément qu'elle est aujourd'hui un puissant moyen d'affirmation, mais qu'elle fut longtemps pesanteur et empêchement. Nous la chérissons tout en n'étant pas toujours certains de sa valeur sur le plan universel. Nous avons l'impression de "venir de loin à la conscience ", pour le dire comme Dumont, et nous nous expliquons difficilement les raisons de la longue hibernation dont l'après-guerre aurait été le point culminant. Notre culture est donc tout à la fois trésor enfoui, objet d'une certaine honte, motif de fierté et, plus fondamentalement encore, le lieu d'un questionnement dans lequel se rejoignent en des sentiments mêlés la fierté de notre être singulier et résilient ainsi que le souvenir honteux de notre inaptitude à la modernité.

Ce rapport problématique à la culture et à ses déficiences alléguées traverse toute notre histoire, mais c'est avec la critique de la Grande Noirceur que le procès qu'on lui intente atteindra son paroxysme. Je voudrais maintenant examiner l'hypothèse selon laquelle le constat d'une déficience inscrite au cœur de la culture était non seulement présent au moment de ladite Grande Noirceur, mais qu’en réalité il s’y trouvait exprimé de manière encore plus exacerbée qu'au cours de la Révolution tranquille. Plusieurs penseurs de la condition québécoise ont montré que c'est de l'intérieur même de la Grande Noirceur que s'amorçait sa déconstruction'. On trouve en effet dans la " pensée politique ${ }^{10}$ " des années 1950 l'analyse la plus implacable

9 Voir, notamment, Marcel Fournier, L'entrée dans la modernité, Éditions Albert Saint-Martin, Montréal, 1988; Yvan Lamonde et Esther Trépanier, L'avènement de la modernité culturelle au Québec, Montréal, Institut québécois de recherche sur la culture, 1986.

10 L'analyse la plus impitoyable de la «pensée politique » canadienne-française dont la Grande Noirceur serait le point culminant se trouve dans les ouvrages que signe 
des insuffisances de la culture canadienne-française et des idéologies qu'elle aurait portées. En cela, c'est peut-être dans le regard que la Grande Noirceur jette sur elle-même que se trouve, entre 1950 et 1960 , le moment paroxystique du rapport négatif à la culture canadienne-française.

\section{Les années 1960 : critique d'une culture " colonisée "}

Mais commençons par le commencement et revoyons la critique que la Révolution tranquille adressera à la période qui la précède. Alors qu'elle battait son plein, Marcel Rioux a proposé une tripartition dans l'histoire des idéologies au Québec au sein de laquelle la période 1840-1945 correspondrait à l' "idéologie de conservation ", alors que celle qui s'étend de 1945 à 1960 aurait été dominée par l'" idéologie de contestation et de rattrapage ${ }^{11}$ ". La notion d'idéologie de conservation décrit on ne peut mieux ce que le sens commun tout autant que les sciences sociales naissantes (la Faculté des sciences sociales de l'Université Laval est fondée en 1943) entrevoyaient comme cette stagnation qui aurait frappé le monde canadien-français depuis le $\mathrm{XIX}^{\mathrm{e}}$ siècle. C'est le défi qui attendrait les révolutionnaires tranquilles que de lever l'hypothèque que représentait cet attachement atavique et improductif au passé. Car s'il est une certitude au lendemain de la mort de Duplessis, c'est que la fidélité au passé n’est plus garante de la survivance de la collectivité. C'est bien ce qu’annoncent le « Désormais » qu'aurait lancé Paul Sauvé à l'automne de $1959^{12}$ et les premières politiques que mettra en place l'" équipe du tonnerre " de Jean Lesage. Le fait est cependant que, dans le triptyque proposé par Rioux, la Grande Noirceur est placée sous les

Pierre Elliott Trudeau au cours des années 1950 et, en particulier, dans Le fédéralisme et la société canadienne-française, Montréal, Hurtubise HMH, 1967.

11 Marcel Rioux, "Sur l'évolution des idéologies au Québec ", Revue de l'Institut de sociologie, $\mathrm{n}^{\circ} 1$ (1968), p. 95-124.

12 Pour une remise en question de la paternité de cette parole historique, voir Alexandre Turgeon, "Et si Paul Sauvé n’avait jamais prononcé le "Désormais...” ? ", Revue d'histoire de l'Amérique française, vol. 67, nº 1 (été 2013), p. 33-56. 
notions de " contestation " et de "rattrapage ». C'est dire que les penseurs de la Révolution tranquille sont disposés à reconnaître que la dynamique de modernisation des années 1960 dont ils seraient à l'avant-garde trouve sa source dans la décennie précédente. Nous verrons bientôt que la Grande Noirceur jette sur elle-même un regard moins indulgent.

L'essentiel de la critique de la décennie de 1960 est mêlé de rejet du monde canadien-français et de célébration de la modernité ${ }^{13}$. La création du ministère de la Culture en 1961 témoigne en cela de deux réalités. D’un côté, sa mise en place exprime la nécessité d'actualiser la culture canadienne-française. Elle sera désormais prise en charge par l'État, qui en fait un projet volontariste au service de la collectivité. On ne saurait sous-estimer la signification de ce déplacement. La vieille culture canadienne-française faisait corps avec la collectivité. Être canadien-français signifiait être investi à son insu et au plus profond de soi par ce qui constituait pour ainsi dire «naturellement » le fait d'être canadien-français. La culture était de la sorte entièrement métabolisée et constitutive de l'être. On peut dire, dans la perspective inverse, qu'elle ne s'érigeait pas en objet, qu'elle ne possédait pas cette extériorité qu'allait lui conférer un ministère voué à la promotion, au développement et, plus largement, à la prise en charge collective de ce qui se donnait dès lors comme objet de connaissance et vecteur d'émancipation de la collectivité. Le ministère de la Culture incarnait dans sa réalité même la critique de la culture

13 Voir, à ce titre, les nombreux ouvrages jetant sur la Révolution tranquille ce même regard rétrospectif faisant d'elle la renaissance d'un Québec s'ouvrant enfin à la modernité ou contestant cette thèse : Guy Berthiaume et Claude Corbo (dir.), La Révolution tranquille en héritage, Montréal, Éditions du Boréal, 2011; Yves Bélanger, Robert Comeau et Céline Métivier (dir.), La Révolution tranquille 40 ans plus tard: un bilan, Montréal, VLB éditeur, 2000 ; É.-Martin Meunier et Jean-Philippe Warren, Sortir de la "Grande noirceur " : l'horizon "personnaliste " de la Révolution tranquille, Québec, Éditions du Septentrion, 2002; Kenneth McRoberts et Dale Postgate, Développement et modernisation du Québec, Montréal, Éditions du Boréal Express, 1983; Jean-Louis Roy, La marche des Québécois, le temps des ruptures (1945-1960), Montréal, Leméac Éditeur, 1976. 
canadienne-française issue de l'hiver de la survivance et de l'idéologie de conservation. Si, en effet, il fallait se déprendre de l'impuissance dans laquelle leur vieille culture avait apparemment plongé les Canadiens français, il était nécessaire de l'arracher à l'ordinaire des choses, il fallait la dénaturaliser, la séparer du sujet qui la portait de manière à la poser tout à la fois comme enjeu, objet de connaissance et comme condition à la refondation de la collectivité.

La mise sur pied du Ministère impliquait autre chose : le fait que, dès ses premiers jours, la Révolution tranquille se dépêchait de doter le Québec de cet instrument par le truchement duquel la société allait apercevoir, comme dans un miroir grossissant, ce qui la distinguait des autres, ce qu'il fallait protéger et en même temps affirmer et qui posait encore une fois la culture au centre de l'existence sociale. De la même manière que, depuis toujours, le désir de durer s'était appuyé sur la défense acharnée d'une culture canadienne-française gardienne de la singularité de la collectivité et, en même temps, écran protecteur face aux effets prétendument dissolvants de la culture anglo-protestante du continent, l'émancipation des Québécois que la Révolution tranquille proposait semblait, comme autrefois, devoir passer par la culture.

Le rapport à la culture dans ce nouveau contexte est évidemment très différent de ce qu'il était antérieurement, mais il est frappant de constater que subsiste la certitude ancienne selon laquelle le destin de la collectivité, celle de ces Québécois nouveaux que la Révolution tranquille est en train de mettre au monde tout comme celle que formaient les Canadiens français de jadis, s'organise dans l'autointerprétation culturelle que la collectivité se donne d'elle-même. La question consistera à savoir de quelle manière il faudra réinventer la culture pour qu'elle soit ferment de libération et pierre d'angle de la refondation identitaire de la société québécoise. Cependant, plutôt que de tenter de récupérer l'essentiel de l'expérience historique canadienne-française telle que la culture du monde canadien-français l'avait établie, la Révolution tranquille va s'atteler à son démantèlement, à la fois malhabile et délétère. Malhabile d'abord parce qu'on 
ne sait que faire de l'héritage canadien-français dont on veut se distancier alors même que l'on pressent confusément les dangers de la tabula rasa. De Claude Gauthier à Gilles Vigneault, on oscillera entre la célébration folklorique du draveur et de la sagesse paysanne et le rejet concomitant de toutes références à cette histoire irrémédiablement associée à l'arriération de la collectivité. Délétère ensuite parce que le projet de refondation identitaire auquel se consacre la Révolution tranquille trouve en 1960 l'an 1 de l'histoire québécoise, dorénavant privée de l'arrière-plan nécessaire à la fabrication d'un monde commun dans lequel Canadiens français et Québécois se retrouveraient liés par une communauté de destin.

\section{Une culture à réinventer}

C'est un rapport trouble à la culture qu'annonce ainsi la Révolution tranquille. L'idéologie de conservation telle que l'a conceptualisée Rioux avait peut-être enfermé les Canadiens français dans ce conservatisme que l'on ne finira plus de décrier à partir des années 1950, mais elle avait eu l'avantage de conforter un certain nombre de certitudes quant à l'identité collective. C'est cette vieille assurance de constituer une société singulière en Amérique et, à certains égards, meilleure que les autres (moins matérialiste, plus vertueuse, plus modeste et moins superficielle) que venait mettre à mal la critique que lui adressait désormais la Révolution tranquille. Sous les coups de boutoir qu'elle lui assénait, le monde canadienfrançais n'apparaissait plus que dans ses faiblesses et ses lacunes. Comme en un étonnant renversement de l'ordre des choses, les vertus d'autrefois se voyaient imputer la responsabilité du " retard du Québec ${ }^{14}$ ", la fidélité aux traditions n’étaient plus que conservatisme paralysant et l'Église, à qui l'on avait toujours reconnu d'avoir été gardienne du monde canadien-français, devenait respon-

${ }^{14}$ Voir, à ce sujet, les textes révélateurs regroupés dans René Durocher et Paul-André Linteau (dir.), Le "retard " du Québec et l'infériorité économique des Canadiens français, Montréal, Éditions du Boréal Express, 1971. 
sable de notre assujettissement à un ordre social qui nous avait faits moutons dans un continent de lions.

On pouvait dès lors se demander pour quelles raisons tout cela avait été possible. Pourquoi tant de soumission, d'obéissance et de refus de la modernité? À côté de ces constats éplorés et rageurs de l'impuissance collective que la culture aurait tout à la fois engendrée, reproduite et justifiée au nom de la survivance, un important travail d'autojustification allait s'amorcer. Une large part de la critique sociale des années 1960 trouvera ainsi dans la thèse du colonialisme un certain soulagement de la mauvaise conscience qu'inspirait la critique impitoyable de cette culture canadienne-française à laquelle on était maintenant disposé à tourner le dos ${ }^{15}$. C'est parce que nous avions vécu sous le joug colonial que notre culture avait été empêchée d'éclore dans la modernité qui s'affirmait dans les autres collectivités d'Amérique. Si l'Église nous avait dominés et avait pu imposer le conservatisme débilitant sur lequel on s'abattait, c'est qu'il fallait bien s'abriter en elle face au danger de l'assimilation au monde angloprotestant. Si nous avions été si rétifs au changement, c'est que les moyens d'affronter l'inédit avec confiance nous faisaient défaut. Peuple de prolétaires, nous étions privés de l'accès au capital et coupés des grands réseaux du capitalisme anglais. Surtout, si notre culture était si pauvre, c'est que le confinement dans l'agriculture, puis la prolétarisation massive ne nous avaient pas conduits à valoriser l'éducation, le commerce, la science et la technique. Le colonialisme nous avait réservé les rôles subalternes, ceux de porteurs d'eau, de scieurs de bois et de journaliers.

Cette vue des choses offrait l'avantage de soulager en partie de la culpabilité qui accompagnait la critique des insuffisances de jadis. Ce n'était pas entièrement notre faute si notre culture paraissait si inadaptée avec le recul de la Révolution tranquille. Nous avions été

15 L'archétype de la thèse qui fait du Québec une société dominée historiquement par le colonialisme se trouve dans André D'Allemagne, Le colonialisme au Québec, Montréal, Éditions R. B., 1966. 
dominés par le colonisateur anglais, et l'Église lui avait servi de relais. Que pouvions-nous faire dans un tel état d'infériorité? Comment notre culture aurait-elle pu s'épanouir? Fortement tributaire des travaux de Frantz Fanon, de Jacques Berque et d'Albert Memmi ${ }^{16}$ dont l'influence était grande au début des années 1960, cette interprétation de la condition québécoise avait pour effet de politiser ce qui avait été abordé jusque-là du seul point de vue des caractéristiques intrinsèques de la culture. Culture empêchée, donc, en raison de déficiences internes, mais aussi, et peut-être surtout, à cause de l'oppression dont elle aurait été victime depuis la Conquête.

Ce rapport ambigu à la culture se traduit dans la représentation apparemment contradictoire d'une culture à la fois médiocre et colonisée à laquelle il conviendrait paradoxalement de redonner ses lettres de noblesse. Ainsi, par exemple, à côté de la critique acerbe et continue du joual en tant que dialecte dégénéré, se trouve sa mise en valeur dans une perspective de redécouverte moderne et assumée d'un langage exprimant la singularité culturelle de la collectivité. À la dénonciation vigoureuse du joual et de ses effets délétères s'oppose cette conception nouvelle, largement inspirée par la thèse du colonialisme, selon laquelle le joual constituerait un genre de langue nationale et exprimerait les profondeurs de l'âme québécoise. Il témoignerait également, dans son lexique et sa syntaxe empruntés en partie à l'anglais, du parcours historique canadien-français.

C'est dans cette perspective que l'on peut appréhender les réactions très vives que provoque la pièce Les belles-sceurs de Michel Tremblay en 1968. Alors que la critique du joual s'était radicalisée depuis celle que lui avait adressée André Laurendeau en $1959^{17}$ et

16 Sur cette question les ouvrages les plus influents de la période sont Albert Memmi, Portrait du colonisé, précédé du Portrait du colonisateur, suivi de Les Canadiens français sont-ils des colonisés?, Montréal, Éditions l'Étincelle, 1972; Frantz Fanon, Les damnés de la terre, Paris, La Découverte, 2002; Jacques Berque, Dépossession du monde, Paris, Seuil, 1964 et, dans un registre un peu différent, Pierre Vallières, Nègres blancs d'Amérique, Montréal, Éditions Parti pris, 1969.

17 André Laurendeau, "La langue que nous parlons », Le Devoir, 21 octobre 1959, p. 4. 
dans la foulée, celle du frère Untel ${ }^{18}$, voici que les années 1960 proposeront une interprétation plus positive du phénomène. " $O n$ est fondateur d'une nouvelle langue ", avait lancé l'un des élèves du frère Untel à propos du joual. Voilà qui anticipait le retournement dont le débat suscité par la pièce de Tremblay allait être le point culminant. Le joual n'exprimait-il pas à sa façon l'expérience historique canadienne-française? N'était-il pas jusque dans sa médiocrité manifeste le témoin de la condition québécoise en même temps que, pour ceux qui savaient entendre, l'appel au dépassement de l'infériorité des Canadiens français? Au lendemain de la première des Belles-sœurs, c'est un Jean Basile dithyrambique qui écrit dans Le Devoir que « le “joual" [...] peut prendre des dimensions dans le temps et dans l'espace qui font de lui l'arme la plus efficace qui soit contre l'atroce abâtardissement qu'il exprime ${ }^{19}$ ".

Ce point de vue sera largement présent dans les pages de la revue Parti pris, l'un des principaux vecteurs de la thèse du colonialisme. Le joual y est signe de l'oppression coloniale dans la mesure où les Canadiens français auraient été dépossédés de la langue française au cours de leur histoire de colonisés, en même temps qu'objet de revendication identitaire ${ }^{20}$. En attendant que l'indépendance nationale ne redonne aux Québécois l'usage du français, on estimait devoir considérer le joual comme une langue de transition témoignant de la sujétion collective. On trouvera de vigoureux défenseurs de la beauté du joual au cours des années 1960, mais, pour l'essentiel, la critique consistera à en reconnaître les lacunes en même temps qu'on l'absoudra de ses tares en voyant en lui le surgeon de l'oppression coloniale.

${ }^{18}$ Jean-Paul Desbiens (alias frère Untel), Les insolences du frère Untel, Montréal, Éditions de l'Homme, 1960.

19 Jean Basile, "Les belles-sœurs de Michel Tremblay : une entreprise familiale de démolition ", Le Devoir, 30 août 1968.

${ }^{20}$ Voir, notamment, Gérald Godin, "Le joual et nous ", Parti pris, vol. 2, n ${ }^{\circ} 5$ (janvier 1965); et du même auteur, «Le joual politique ", Parti pris, vol. 2, nº 7 (mars 1965). 
C'est là le rapport complexe à la culture qui se développe au cours de la Révolution tranquille. La critique est certes sévère. Sans doute cela était-il inévitable dans ce Québec dont la refondation identitaire exigeait peut-être ce genre de moment zéro de l'existence collective. Sans doute fallait-il, comme Dumont l'a prétendu, que s'exprime dans cette révolution de la parole le dépit accumulé au fil des générations devant tant d'empêchements. Il fallait révéler la nature de ce qui nous bridait collectivement. C'est dans la culture que l'analyse a trouvé les raisons de la petitesse de l'existence collective. Elle aura appliqué la thèse de la sujétion coloniale comme un baume sur la douleur que suscitaient les lacunes de la culture.

Dans cette vue des choses, le mal provient, en partie du moins, de l'"extérieur ". La Conquête et la longue histoire de domination qu'elle inaugure exercent sur la culture les effets débilitants affectant toute culture dominée. Nous avions été les victimes d'une histoire qui nous vouait à l'assimilation et qui avait déprécié notre être collectif, en même temps que nous avions été incapables jusqu’aux premières clartés de la Révolution tranquille de trouver en nous-mêmes les moyens de dépasser l'insignifiance culturelle à laquelle nous avait condamnés la situation défavorable dans laquelle l'histoire nous avait placés.

Cette analyse très dure de la culture canadienne-française que l'on cherche en même temps à dédouaner, les années 1950 s’y étaient déjà attelées. Intransigeantes, elles n'avaient cependant pas trouvé d'échappatoire à l'arriération qu'elles constataient.

\section{Les années 1950 : le temps du dépit}

Sur le plan sociologique, la période qui va grosso modo de la grève de l'amiante (1949) à la prise du pouvoir par le Parti libéral dirigé par Jean Lesage (1960) est l'une des plus riches de l'histoire du Québec. Elle incarne à la fois la "Grande Noirceur ", au sens strict du terme, et sera le théâtre de la critique sans doute la plus radicale de la culture canadienne-française. 
La période est dominée par le sentiment très répandu parmi les élites d'un " retard ", d'une inadéquation des idéologies et des attitudes culturelles. Surtout, la nécessité s'impose à plusieurs de faire éclater le cadre contraignant que dresse un traditionalisme déphasé par rapport à une société irrémédiablement engagée dans une dynamique d'industrialisation et d'urbanisation. C'est sans doute en raison de l'urgence que ressentent les "définisseurs de situation " et afin d'échapper au "statisme ", comme le dira en 1953 Jean-Charles Falardeau, sociologue de premier plan au cours de la décennie et lui aussi critique du conservatisme ambiant ${ }^{21}$, que la critique de cette Grande Noirceur qui ne connaît pas encore son nom sera si virulente.

Nous avons aperçu que la critique que développera plus tard la Révolution tranquille avait trouvé dans l'expérience coloniale le motif d'une certaine déculpabilisation. Dans cette perspective, nous aurions été coupables d'un attachement pathologique à nos traditions dépassées, mais cet attardement traditionaliste et irrationnel avait été préparé de loin par la domination coloniale que le monde canadien-français avait subie. Mais pour que cette thèse puisse émerger, il fallait qu'apparaissent au même moment les travaux portant sur la décolonisation en Afrique, au Maghreb et en Asie du Sud-Est. Les années 1950 ne disposent pas de cet argument compensatoire. Le jugement que la période porte sur la culture en est d'autant plus implacable.

Peut-on affirmer pour autant que l'invocation de l'histoire soit totalement absente de l'analyse des inaptitudes collectives au cours de cette période? En d'autres termes, la Grande Noirceur ne cherchet-elle pas elle aussi à se justifier en rappelant les effets négatifs de l'histoire sur la constitution de la culture canadienne-française? On peut être tenté de répondre par l'affirmative à ces questions si l'on considère le fait que, même Pierre Elliott Trudeau, l'un des critiques

${ }^{21}$ Certains des textes les plus importants de Jean-Charles Falardeau ont été regroupés dans Simon Langlois et Robert Leroux, Sociologie du Québec en mutation : aux origines de la Révolution tranquille, Québec, Les Presses de l'Université Laval, 2013. 
du traditionalisme les plus virulents de sa génération, ne pourra éviter d'invoquer la situation défavorable dans laquelle l'histoire a placé les Canadiens français. L'essentiel de sa thèse est à l'effet que le rapport à la démocratie relève de la tare historico-génétique, les Canadiens français ayant joué le jeu des institutions britanniques sans adhérer aux valeurs morales qui les sous-tendent ${ }^{22}$. Toujours, ils auraient, pour tirer leur épingle du jeu, instrumentalisé les institutions dans le cadre d'une joute politique mesquine et entièrement orientée vers la défense d'intérêts ethniques. Le Québec duplessiste, incarnation politique de la Grande Noirceur, ne serait alors que le prolongement de cette inaptitude et le néonationalisme qu'inaugure la Révolution tranquille, la nouvelle expression de cette dérive. Trudeau reconnaîtra néanmoins que, si les Canadiens français se sont enfermés dans cet ethnicisme délétère et contraire aux idéaux démocratiques qu'ils auraient dû cultiver, c'est en partie parce que les anglophones ne leur ont jamais véritablement ouvert l'accès aux institutions démocratiques. Il reproche donc aux Canadiens français leur désintérêt pour la démocratie, désintérêt qu'il fait remonter des profondeurs de leur culture catholique et nationaliste.

La réflexion de Trudeau s'infléchira quelque peu au cours des années 1960. Il demeurera aussi profondément réfractaire au nationalisme dans lequel il continuera de reconnaître les ferments d'un ethnicisme dangereux en même temps que les signes de la perpétuation du repli sur soi canadien-français. Mais il constate également que le rapport à la démocratie a changé dans le Québec de la Révolution tranquille et que les Québécois peuvent désormais participer sur un pied d'égalité avec les autres Canadiens à l'édification du fédéralisme ${ }^{23}$.

22 Trudeau se penche sur la culture politique québécoise dans Le fédéralisme et la société canadienne-française publié en 1967. Mais le texte principal de ce livre, «De quelques obstacles à la démocratie au Québec ", a été publié une première fois en 1958 et reprend, pour l'essentiel, sa conférence de 1954 à l'Institut canadien des affaires publiques.

${ }^{23}$ Voir, à ce sujet, Mélanie Ouellette, "Les Canadiens français, l'histoire et la démocratie : l'interprétation de Pierre Elliott Trudeau ", Mens : revue d'histoire 
Que même Trudeau doive admettre en 1968 que le Québec a acquis une certaine maturité sur ce point montre que la colère contre la vieille culture canadienne-française s'est un peu apaisée.

Jean-Charles Falardeau s'abat sans ménagement sur « ce système de pensée qui les empêche (les Canadiens français) de vivre dans le présent $^{24}$ ». Lui aussi trouvera dans l'arrière-plan historique québécois des éléments susceptibles d'expliquer la propension au "statisme" qu'il constate et déplore tout à la fois. L'histoire des peuples minoritaires, explique-t-il, est une « histoire ethnocentrique ${ }^{25}$ ». Comme Trudeau, il condamne la tendance au repli sur soi et la mentalité d'assiégé qui domine le monde canadien-français depuis la Conquête. Comme lui encore, il observe le peu d'inclination à la démocratie de la collectivité. Les explications qu'il en donne sont grosso modo les mêmes. La peur de l'assimilation et la résistance qu'elle engendre expliqueraient en partie la cristallisation identitaire conjuguant en un dogmatisme rigide l'origine française et catholique, la vocation rurale, la mission providentielle et l'instrumentalisation des institutions politiques britanniques. Il n'est pas étonnant dans ce contexte qu'aient été " privilégiés les préceptes d'ordre et de soumission ". Il n'est pas plus surprenant que les Canadiens français n'aient pas eu l'occasion de « s'initier au self-government ou de pratiquer l'initiative démocratique ${ }^{26}$ ".

L'histoire canadienne-française a donc partie liée avec l'attardement traditionaliste que déplorent plusieurs intellectuels des années 1950. Guy Rocher expliquera pour sa part que, si le paysan de Nouvelle-France et, plus tard, canadien-français, est intrinsèquement conservateur, c'est que sa culture est imprégnée des attitudes et des conceptions issues de l'Ancien Régime et que la fragilité de son

intellectuelle de l'Amérique française, vol. 1, n 1 (automne 2000), p. 37-50.

${ }^{24}$ Langlois et Leroux, Sociologie du Québec en mutation, p. 296.

25 Ibid., p. 286.

${ }^{26}$ Ibid., p. 294. 
existence l'aurait incliné à la prudence plutôt qu'à l'expérience de la nouveauté27.

Toutefois, la plupart des analystes de la période ne fonderont pas leur critique de la culture en la rattachant directement à l'histoire canadienne-française de manière à l'absoudre de ses travers. Il tient de l'évidence que la Conquête et la domination anglaise ont pesé de tout leur poids sur le destin canadien-français, mais la colère est telle au cours de cette décennie à l'égard de la paralysie qui semble avoir frappé la collectivité que le rôle qu'aurait pu jouer l'histoire semble secondaire. En d'autres termes, les avanies d'une histoire adverse ne peuvent servir d'alibi aux tares qui affectent la culture. Les Canadiens français n'avaient alors qu'eux à blâmer pour le retard qu'ils avaient accumulé dans la course à la modernité dans laquelle s'étaient apparemment engagées d'autres sociétés.

\section{La culture comme seule coupable}

On assiste, au cours des années 1950, à la critique d'une culture " idéaliste ", déconnectée et insensible aux enjeux concrets auxquels est confrontée la société. Les insolences du frère Untel, opuscule dans lequel se trouve la critique du joual la plus incisive des années 1950 et 1960, témoigne éloquemment du dépit qu'inspire la pauvreté de la culture canadienne-française. Car c'est bien elle que vise, une fois encore, la diatribe du frère Untel. Si le joual a pu s'imposer, c'est que se trouve à la source de cette dérive aux effets délétères un "problème de civilisation ${ }^{28}$ ". Le joual a pu s'imposer parce que la " civilisation " canadienne-française est " joual » elle-même. La dominance de ce langage abâtardi ne serait rien d'autre que l'expression d'une paresse plus profonde, d'une propension atavique au laisser-aller. Cela veut dire, explique encore le frère Untel, que notre collectivité vit sous le règne de la facilité et de la médiocrité. Nulle part ailleurs que dans ce passage, où se trouve mis en relief le lien entre joual et crise de

27 Guy Rocher, Le Québec en mutation, Montréal, Hurtubise HMH, 1973, p. 30-31.

${ }_{28}$ Desbiens, Les insolences, p. 26. 
civilisation, n'apercevrons-nous mieux la thèse des Insolences : "Le langage est le lieu de toutes les significations. Notre inaptitude à nous affirmer, notre refus de l'avenir, notre obsession du passé, tout cela se reflète dans le joual qui est vraiment notre langue ${ }^{29}$. "

Le refus d'advenir à nous-mêmes et l'absence de toutes perspectives émancipatrices ont partie liée avec le joual : c'est en nous-mêmes que se trouveraient les raisons de notre médiocrité. Au Canada français, la culture n'aurait pas vocation d'élever l'âme, et le langage n'aurait pas pour tâche de relier la collectivité à l'universel. Tous deux emprisonneraient dans l'univers autoréférentiel d'un Québec qui ne serait que "Rock'n Roll, hot-dog et ballade en auto ${ }^{30}$ ». Nulle trace ici de la consolation que les révolutionnaires tranquilles trouveront bientôt dans la thèse un tant soit peu apaisante d'un colonialisme castrateur. Le frère Untel se refuse à tout faux-fuyant. Le joual tout autant que la culture du hot-dog témoigneraient d'une même démission. Cette critique sans concession appartient pleinement à l'esprit des années 1950. La collectivité s'y trouve renvoyée à ellemême de telle manière que les effets d'une histoire adverse ne sauraient servir de justification aux défauts du monde canadien-français.

Lorsque le frère Untel évoque la crise de civilisation que refléterait la piètre qualité de la langue parlée au Québec, c’est la paresse collective qu'il voue aux gémonies. Le relâchement qui conduit à prononcer « joual » au lieu de " cheval » est aussi celui de l'esprit et le signe de notre "pauvreté d'âme ". Le jugement sévère qu'assène le frère est sans retour : «Pour échanger entre primitifs, une langue de primitifs suffit $^{31} »$. La piètre qualité de la langue, préoccupation partagée par Pierre Vadeboncoeur notamment, illustrerait donc comme un symptôme la maladie qui rongerait la culture.

Il en va de même du jugement que porte le frère Untel à l'égard de l'enseignement de la philosophie dans les facultés universitaires.

29 Ibid., p. 25.

30 Ibid., p. 26.

31 Ibid., p. 25. 
Ici, ce n'est pas tant la pauvreté de la culture que l'on y transmet qui est en cause, mais l'écart qui sépare cet enseignement de la vie qui bat. Le chapitre des Insolences consacré à la pensée canadiennefrançaise est truffé de constats dépités quant à la "paralysie de la pensée ", d'évaluations rageuses au sujet de la recherche de « la pureté par la stérilisation ${ }^{32}$ ». Bref, écrit-il encore, "le reproche que je fais à la Faculté de philosophie de Laval, c'est d'être déracinée ${ }^{33}$ ". On le verra, ce reproche que les contempteurs de la Grande Noirceur lui adresseront alors qu'elle bat son plein est généralisé.

Le frère Untel n' ignore certainement pas les raisons sociologiques et politiques qui sont à la source des tares collectives qu'il relève, mais son pamphlet ne les évoque jamais. Plus exactement, lorsqu'il la convoque, c'est l'histoire longue de l'Église catholique qui le retient, le type de catholicisme dont les Canadiens français auraient hérité et ses effets corrosifs sur toute pensée tournée vers l'action. Mais on voit bien que sont absents de son analyse les effets de la Conquête et de la domination politique qui va se bâtir tout au long du XIX ${ }^{\mathrm{e}}$ siècle. Le frère Untel n'ignore pas l'importance de cette histoire sur le destin canadien-français, seulement il fait le choix d'aller directement aux manifestations de la maladie et refuse de trouver dans cette histoire de domination le prétexte à l'ineptie de la culture canadiennefrançaise. Écrit à la toute fin des années 1950 et alors même que pointent à l'horizon les premières clartés de la Révolution tranquille, Les insolences représente un genre de synthèse de la critique de la Grande Noirceur vue par elle-même.

Ce genre de constat traverse la décennie de part en part. La très grande majorité des intellectuels de l'époque s'entend quant aux fondements culturels de la Grande Noirceur. Tous, comme le frère Untel, désignent d'une manière ou d'une autre une crise de civilisation. Dans La grève de l'amiante, publié en 1956, Trudeau, alors directeur de Cité libre, se livre à un réquisitoire en règle contre l'idéologie

32 Ibid., p. 55.

33 Ibid., p. 57. 
dominante qui paralysait, selon lui, la société canadienne-française. L'antinationalisme viscéral de l'auteur est bien connu, et il n'est guère utile d'y revenir si ce n'est pour souligner que Trudeau voit dans le nationalisme canadien-français, incarné en son temps par le duplessisme, la stratégie des élites canadiennes-françaises cherchant à asseoir leur pouvoir en même temps qu'une forme d'affirmation identitaire à la fois stérile et retardataire.

Il est plus intéressant de s'arrêter aux considérations auxquelles s'adonne le futur premier ministre portant sur ce qu'il appelle la "pensée sociale ». Cette dernière, "fut tellement idéaliste, tellement a prioriste, tellement étrangère aux faits, et pour ainsi dire tellement futile, qu'elle ne réussit à peu près jamais à prendre corps dans des institutions dynamiques et vivantes ${ }^{34}$ ".

On ne trouvera pas beaucoup de condamnation plus sévère de la culture canadienne-française. En même temps, force est de constater qu'elle traduit l'air du temps dans ce Québec qui prend conscience, depuis la fin de la guerre, que la survivance devra maintenant emprunter d'autres voies que celles qu'avait dessinées la tradition. Au même moment, Trudeau est convaincu des mérites de l'interventionnisme de l'État et de la régulation sociale providentialiste. Nous savons que c'est cette conviction qui fera de lui l'un des défenseurs du fédéralisme les plus constants de sa génération puisque, dans son esprit, c'est à partir du gouvernement central que pouvait se déployer l'État keynésien qu'il appelait de ses vœux. Mais sa critique de la culture canadienne-française ne se limite pas à celle du nationalisme auquel il impute les motifs du retard du Québec. C'est bien la pensée sociale dans son ensemble qu'il met en cause.

La critique de la Grande Noirceur, au cours des années 1950, n'est donc pas celle que formuleraient des fédéralistes dans le seul but de favoriser l'éclosion d'une État fédéral moderne et capable de tirer le Québec de sa torpeur traditionaliste. Pierre Vadeboncoeur, ardent nationaliste qui se trouvera bientôt du côté des souverainistes,

${ }^{34}$ Pierre Elliott Trudeau (dir.), La grève de l'amiante, Montréal, Éditions du Jour, 1970, p. 11. 
n'en partage pas moins le même point de vue que celui de Trudeau. Notre peuple, écrit-il, " périclite dangereusement dans sa culture ${ }^{35}$ ". Plusieurs passages de La ligne du risque, son opus magnum, résonnent des mêmes constats dépités que ceux que l'on retrouve presque identiques chez Trudeau et le frère Untel. Il vaut la peine de citer longuement ce passage d'un article de 1952 que Vadeboncoeur fait paraître dans Cité libre et dans lequel il se penche à son tour sur ce que ses coreligionnaires modernistes désignent sous la figure d'une crise de civilisation et de la pensée sociale :

La décadence dont il est ici question, ce n'est pas celle, banale, que l'on doit imputer à des causes extérieures, par exemple aux facteurs de contamination par l'étranger; non, il s'agit d'une erreur d'intelligence et de vie, et d'une très grave erreur d'enseignement, que l'on peut préciser ainsi : la culture a cessé de savoir où se trouve l'homme, quelles sont ses puissances et quoi lui révéler de désirs et de forces sous les espèces de l'idéal; notre culture a totalement négligé de fouetter les puissances de l'homme ${ }^{36}$.

La critique est frontale : cette culture ne sait plus " où se trouve l'homme ", à force d'être étrangère à la vie elle-même, à l'univers de l'idéal et du désir. La décadence dont il est question fait signe en direction de la " crise " que définissent Les Insolences et La grève de l'amiante.

La même année, Jean-Charles Falardeau s'exaspère lui aussi de l'inadaptation des idéologies. On est frappé par les ressemblances que sa critique partage avec celle de plusieurs de ses contemporains alors qu'il constate que la société canadienne-française a trouvé "l'expression de son idéal politique en des formules théoriques et absolues. Une même attitude rétrospective, dénuée de réalisme, sinon d'imagination créatrice, se retrouve à l'origine d'un grand nombre d'actions dans la vie contemporaine du Canada français ${ }^{37}$ ».

35 Pierre Vadeboncoeur, "La ligne du risque ", dans La ligne du risque, Montréal, Hurtubise HMH, 1977, p. 97.

36 Ibid., p. 97.

37 Langlois et Leroux, Sociologie du Québec en mutation, p. 198. 
On pourrait multiplier les exemples de ces constats univoques quant au déphasage de la culture. Tous montreraient que la Grande Noirceur avait non seulement conscience d'elle-même, mais qu'elle s'adressait une critique plus draconienne encore que celle qui circulera au cours de la Révolution tranquille. Si cette critique est plus sévère que celle des années 1960, c'est parce que ce qui se trouve incriminé vient de l'intérieur : ce sont les tares collectives, l'impuissance à s'extirper d'un idéalisme apparemment étranger aux réalités du monde contemporain qui caractérisent l'être collectif et le définissent comme être incomplet, mésadapté et imperméable aux réalités d'une modernité en train de se faire sans lui.

En avançant la thèse selon laquelle le colonialisme serait à la source de la domination économique, politique et culturelle du Québec, les intellectuels de l'École historique de Montréal font exception dans cette critique à l'unisson de la crise de la culture canadienne-française ${ }^{38}$. La condition canadienne-française trouve sous leur plume une interprétation qui se démarque par son caractère social et politique. Si le Québec est sous l'emprise de ces " trois dominantes " de la pensée canadienne-française que sont l'agriculturisme, l'antiétatisme et le messianisme ${ }^{39}$, c'est que la domination qu'exerce sur lui le colonialisme anglais depuis la Conquête l'a poussé à se réfugier dans ces représentations dont on constate alors la désuétude. En cela, les historiens de l'École de Montréal préfigurent la critique nouvelle que formulera la Révolution tranquille. Ces intellectuels dont les principaux travaux sont publiés au cours des années 1950 sont, pour ainsi dire, en avance sur leur temps. Délaissant l'obsession de leurs contemporains pour la culture, leurs travaux annoncent une reformulation de la question du Québec.

${ }^{38}$ Voir, notamment, Jean Lamarre, Le devenir de la nation québécoise selon Maurice Séguin, Guy Frégault et Michel Brunet (1944-1969), Québec, Éditions du Septentrion, 1993.

39 Michel Brunet, "Trois dominantes de la pensée canadienne-française : l'agriculturisme, l'anti-étatisme et le messianisme ", Écrits du Canada français, $n^{\circ} 3$ (1957), p. 31-118. Cet article a été reproduit dans La présence anglaise et les Canadiens, Montréal, Éditions Beauchemin, 1958, p. 113-166. 


\section{Conclusion}

Une question demeure sans réponse au terme de la réflexion que nous avons menée : la Grande Noirceur a-t-elle existé? Le Québec a-t-il traversé avec elle son Moyen Âge pour renaître sous les oripeaux de la modernité avec la Révolution tranquille? Le point de vue que nous avons adopté ne permet pas de répondre à ces questions. Dans la perspective qui est la nôtre, l'essentiel ne consiste pas à montrer, à partir de faits empiriquement vérifiables, la réalité du " retard " du Québec.

Nous nous sommes attardé à l'univers des représentations et avons été attentif à la critique de la culture canadienne-française telle qu'elle s'est déployée au cours des années 1950 et 1960. Est-ce à dire que la réalité sociale n'a pas de consistance en elle-même, qu'elle ne serait que discours, auquel cas il nous faudrait conclure à l'extrême relativité de tout ce qui peut être dit au sujet de l'existence sociale?

Il est évidemment possible d'établir un certain nombre de faits caractéristiques de la société canadienne-française des années 1950 que plusieurs ont rassemblés sous le label de Grande Noirceur. Ces faits, ces données empiriques pointent en direction d'un certain sous-développement économique et matériel ${ }^{40}$. Ils illustrent le retard qu'avait accumulé le Québec en matière d'éducation et de formation. Ils expriment, sur d'autres registres et de manière parfois caricaturale, l'attachement à une vision du monde empreinte d'un certain traditionalisme. On peut bien, si l'on veut, les regrouper sous la notion de Grande Noirceur. Il n'est ni erroné ni illégitime de construire des catégories telles que celles de Grande Noirceur et de Révolution tranquille afin de trouver un sens dans le surgissement de l'inédit et dans les tensions qui traversent la période.

Mais ce que nous avons aperçu également, c'est l'importance du discours et des représentations. C'est en eux que s'articule la critique de la culture que nous avons entrevue et, par cela même, une

${ }^{40}$ Voir, entre autres, Jean-Louis Roy, La marche des Québécois, le temps des ruptures (1945-1960), Montréal, Leméac Éditeur, 1976. 
représentation d'ensemble du parcours historique de la collectivité, parcours à l'intérieur duquel se serait formée une personnalité qui lui serait propre. C'est dire qu'une société n'acquiert consistance à ses propres yeux que dans la capacité qu'elle détient d'apparaître à elle-même dans l'ordre du discours.

La notion de Grande Noirceur constitue un lieu de ralliement au sein duquel la signification du nouvel être-ensemble québécois prend forme à partir de 1960. Cette représentation devient alors aussi consistante, "réelle » si l'on veut, que l'existence matérielle de la collectivité. Elle devient en même temps enjeu, problème et objet de débats.

On peut dire, en d'autres termes, que l'univers des représentations est à la fois tentative toujours reconduite d'élucidation du sens de l'existence sociale et cristallisation d'un rapport à soi qui demandera un jour lui aussi à être démystifié et actualisé, un rapport à soi que les penseurs de demain verront peut-être comme un obstacle à la compréhension d'ensemble du sujet collectif. La question qui consiste à savoir si la Grande Noirceur a bel et bien existé renvoie très exactement à ce phénomène : la Grande Noirceur aura servi longtemps à nous expliquer à nous-mêmes, même négativement, les fondements de notre personnalité collective. La notion suscite maintenant critique et scepticisme. Une chose est certaine cependant, c'est qu'elle aura eu pour effet d'opposer les Canadiens français de jadis aux Québécois d'aujourd'hui.

Nous sommes peut-être au moment de devoir réconcilier ce que nos représentations de la Grande Noirceur, associée au monde canadien-français, et de la Révolution tranquille, associée au monde québécois, ont séparé afin de retrouver le sens du parcours historique de notre collectivité. Autrement dit, sans doute faut-il nouer dans un autre discours une représentation qui réunirait les deux mondes qu'ont séparés la Grande Noirceur d'un côté et la Révolution tranquille de l'autre. 